\title{
Polymyalgia Rheumatica Presenting as Depression: The Role of the History and Physical Examination in Psychiatric Assessment
}

\author{
J.H. Ennis, MSW, MD \\ McMaster University Medical Center \\ J.K. LeClair, MD, FRCP (C) \\ McMaster University Medical Center \\ L. Wadas, BSW, CSW \\ McMaster University Medical Center \\ C. Patterson, MD, FRCP (C) \\ McMaster University Medical Center
}

Follow this and additional works at: https://jdc.jefferson.edu/jeffjpsychiatry

Part of the Psychiatry Commons

Let us know how access to this document benefits you

\section{Recommended Citation}

Ennis, MSW, MD, J.H.; LeClair, MD, FRCP (C), J.K.; Wadas, BSW, CSW, L.; and Patterson, MD, FRCP (C), C. (1993) "Polymyalgia Rheumatica Presenting as Depression: The Role of the History and Physical Examination in Psychiatric Assessment," Jefferson Journal of Psychiatry. Vol. 11 : Iss. 2 , Article 7. DOI: https://doi.org/10.29046/JJP.011.2.004

Available at: https://jdc.jefferson.edu/jeffjpsychiatry/vol11/iss2/7

This Article is brought to you for free and open access by the Jefferson Digital Commons. The Jefferson Digital Commons is a service of Thomas Jefferson University's Center for Teaching and Learning (CTL). The Commons is a showcase for Jefferson books and journals, peer-reviewed scholarly publications, unique historical collections from the University archives, and teaching tools. The Jefferson Digital Commons allows researchers and interested readers anywhere in the world to learn about and keep up to date with Jefferson scholarship. This article has been accepted for inclusion in Jefferson Journal of Psychiatry by an authorized administrator of the Jefferson Digital Commons. For more information, please contact: JeffersonDigitalCommons@jefferson.edu. 


\title{
Polymyalgia Rheumatica Presenting as Depression: The Role of the History and Physical Examination in Psychiatric Assessment
}

\author{
J.H. Ennis, M.S.W., M.D., \\ J.K. LeClair M.D., F.R.C.P. (C), \\ L. Wadas B.S.W., C.S.W., \\ and C. Patterson M.D., F.R.G.P. (C)
}

\begin{abstract}
Surveys have indicated that physical examination is a diagnostic tool that is infrequently used by psychiatrists. This is an unfortunate state of affairs in light of the fact that the bio-psycho-social formulation of health-care problems is integral to the treatment of psychiatric disorders. The situation becomes all the more complex when faced with the high comorbidity of physical and psychiatric illness in the elderly presenting with depression. The physical examination, guided by a detailed history, must be considered an integral part of the assessment of depression in the elderly. A case study of polymyalgia rheumatica presenting as depression is utilized to underscore this imperative.
\end{abstract}

\section{INTRODUCTION}

Depression and its etiology can be difficult to diagnose in elderly patients (1). Clinicians are challenged by the high comorbidity of physical and psychiatric dysfunction in older individuals presenting with mood disorder (2-5). The high prevalence of significant physical factors in the etiology, treatment and prognosis of depression in these people demands that a comprehensive physical review, guided by a detailed history, be included in their assessment. The following case study underscores this imperative.

Jeffrey Ennis, MD, is a senior resident in psychiatry at McMaster University in Ontario, Canada. J.K. LeClair, M.D. is the Head of the Division of Geropsychiatry at McMaster University. L. Wadas, B.S.W., C.S.W. is the Program Coordinator of the Combined Outreach Geriatric Service at Chedoke-McMaster Hospital. C. Patterson, M.D., is Associate Professor and Head of the Division of Geriatric Medicine, McMaster University Medical Center. 


\section{CASE REPORT}

Ms. F was a 66 year old married, obese, non-insulin dependent diabetic with a history of hypothyroidism, peripheral edema, osteoarthritis, and hypertension. Psychiatric history included hospitalization for the treatment of depression in 1970, precipitated by marital discord. The family history was positive for psychiatric disturbance. The patient's mother required long-term psychiatric hospitalization for depression. Premorbidly, Ms. F was an active member of her community and involved in the care of her family. In October of $1991 \mathrm{Ms}$. F noted the gradual onset of aching pain principally affecting her feet, legs, shoulders and arms. She described the pain as being constant and unrelenting, like a "twisting towel." The pain followed no diurnal variation and could not be localized to any joints. Analgesic medication provided no relief of her symptoms. She had no headaches. An attempt was made to bring Ms. $\mathrm{F}$. into the hospital for the purpose of investigating her symptoms and devising a management plan. Investigations were incomplete as the patient left the hospital against medical advice (AMA). At the time of discharge her ESR was $40 \mathrm{~mm} / \mathrm{hr}$.

Over time the patient's pain increased in intensity. In January of 1992 Ms. F. took an overdose of an over-the-counter sleep medication and was brought to an emergency psychiatric unit. She was diagnosed as having a major depression, admitted to the hospital, and treatment with trazodone was initiated. She left the hospital AMA and was noncompliant with treatment.

In February 1992 when it became evident that Ms. F. could no longer care for herself, she was referred to a community based geriatric medical and psychiatric outreach team. The patient was seen in her home by a senior resident in psychiatry (JHE) and a social worker (LW). Ms. F. spent most of her day in bed, requiring assistance in transfers and toileting. She could not walk without assistance.

Throughout the mental status examination Ms. F. pleaded for help to reduce her pain. Her affect was dysphoric and labile with increased intensity. She had decrease in her appetite with weight loss. She suffered from initial, middle and terminal insomnia. There was evidence of anergia and anhedonia, but no suicidal ideation. Thought form was normal and there was no evidence of perceptual disturbances. Cognitive examination was within normal limits.

Given that the patient's primary complaint was pain and her history suggested a physical disorder with a gradual onset, it became evident that in order to understand her mental status a detailed physical examination was required. Due to the physical discomfort that Ms. F. experienced from any movement, she was generally uncooperative during physical examination. Examination revealed an obese, hirsute woman with a BP of 140/80 and slight pitting edema. Diffuse tenderness was elicited by light touch of the shoulders, hips and legs. Examination of range of movement lead to inconsistent findings. She had normal proximal strength in the arms, but mild proximal weakness in the legs. Distal strength was normal. Light touch was intact and proprioception was normal. Deep tendon reflexes were normal and brisk. Plantar responses were flexor. There were inconsistent findings on investigation of vibration sense. The rest of the examination was within normal limits.

Based upon the history and physical findings, organic factors were thought to underlie the patient's depressive symptoms. In light of this the patient agreed to admission to a geriatric assessment unit for further investigation.

Differential diagnosis included diabetic neuropathy, multiple myeloma, polymyalgia rheumatica and polymyositis. All laboratory investigations, imaging tests and electrodiagnostic studies were within normal limits, except for her ESR, which was elevated at $81 \mathrm{~mm} / \mathrm{hr}$. Despite the inconsistent presentation of her pain, a diagnosis of PMR was entertained and a trial of prednisone $5 \mathrm{mg}$. was initiated. Within two days the pain reduced dramatically. She 
became co-operative and pleasant. Her depressive symptoms abated. Ms. F. was discharged shortly thereafter on $15 \mathrm{mg}$. of prednisone and follow-up was arranged with a community based rheumatologist. At the time of discharge her ESR was $45 \mathrm{~mm} / \mathrm{hr}$.

Ms. F remained well at three months post-discharge, having returned to her premobid level of physical and mental function.

\section{DISCUSSION}

In this case the mental status examination was consistent with a major depression existing in the presence of significant physical symptoms. Previous assessments interpreted these somatic complaints as depressive equivalents. However, data from the history, coupled with non-specific physical findings, a high ESR and a dramatic response to low dose prednisone established a diagnosis of a treatable physical disorder: polymyalgia rheumatica (PMR).

PMR is a disease of unknown etiology which occurs in patients over 50 years of age. The annual incidence is approximately $50 / 100,000$ with a prevalence of $1 \%$ in persons over age 50 . Woman are affected twice as often as men. Characteristically, the illness presents with proximal pain in the shoulders and thighs. The pain is worse on awakening and associated with morning stiffness. A detailed history is critical in the diagnosis of PMR since, typically, physical examination does not reveal specific abnormalities. There may be tenderness of the upper arms and thighs with some limitation of range of movement of the shoulders and hips, but without signs of arthritis. Muscle strength is usually normal. Often the patient is unable to cooperate in the muscle examination because of pain. A marked elevation of the sedimentation rate is almost invariably present. A normochromic, normocytic anemia is common (6-8). As well, PMR has been associated with giant cell arteritis (GCA). GCA left untreated can lead to blindness (9). Secondary depression has been identified as a sequelae of PMR in the context of longstanding, untreated disease. In such circumstances the diagnosis becomes more challenging (6). A dramatic clinical response to small doses of steroids is usually seen in PMR. In many patients prednisone may be discontinued in two years (7).

It has been reported that between $30-50$ percent of elderly patients with a physical illness have a comorbid affective disorder (1). In the geriatric population mood disorders may be atypical or masked, with somatic symptoms representing depression rather than organic disease. Neurovegetative symptoms typical of depression can be manifestations of physical illness. It is not surprising that the identification of illness in the elderly is a complicated task that can easily lead to misdiagnosis and treatment. Medical practitioners involved in the care of the elderly must include a detailed history, a mental status examination and a physical examination in the formulation of health care problems.

Physical examination, based upon a patient's history, is a diagnostic tool that appears to be infrequently used by psychiatrists, as indicated by the only published reports on the subject. McIntyre and Romano report that in their survey of psychiatrists in the Rochester, New York area, $8 \%$ frequently performed initial physical 
examination on their outpatients and $13 \%$ frequently performed such an examination on their inpatients (10). Patterson's survey found similar results. None of the responding psychiatrists performed physical examination on new outpatients and only $17 \%$ routinely sought physical examinations of patients through a designee (11).

Psychiatrists' apparent lack of recognition for the importance of including data provided by physical examination, which is guided by a detailed history, in the formulation of illness can have serious consequences (12-13). This is an unfortunate state of affairs in light of the fact that the bio-psycho-social formulation of healthcare problems is integral to the diagnosis and treatment of psychiatric disorders (14-16). The situation becomes all the more complex when faced with the high comorbidity of physical and psychiatric illness in the elderly presenting with depression $(2-3,5)$. In this case presentation, information provided by the history and physical examination, at the point of referral to a psychiatric service, revealed evidence of a primary organic illness in the etiology of the patient's depression. Working in collaboration with specialists in geriatric medicine, the specific nature of the organic illness was identified and appropriate treatment was initiated with a positive outcome. The expert interpretation of data provided by the history and physical examination, in addition to the mental status examination, must be considered an integral part of the assessment of depression in the elderly. What remains to be identified, through additional research, is those elements of the physical examination of the elderly that are likely to lead to the diagnosis of treatable medical illnesses that present as depression.

\section{REFERENCES}

1. Wasylenki D: Depression in Elderly. CMA Journal. 1980; 122:525-533

2. Blazer D: Depression in the Elderly. The New England Journal of Medicine. 1989; 320:164-166

3. Blazer D, Williams DD: Epidemiology of Dysphoria and Depression in an Elderly Population. Am J of Psych. 1980; 137:439-448

4. NIH Consensus Conference: Diagnosis and Treatment of Depression in Late Life. JAMA 1992; 268:1018-24

5. Ouslander JG: Physical Illness and Depression in the Elderly. J Amer Geriatrics Soc. 1982; 30:593-599

6. Cohen MD, Ginsburg WW: Polymyalgia Rheumatica. Rheumatic Disease Clinics of North America. 1990; 16:325-339

7. Spiera H: Giant Cell Arteritis and Polymyalgia Rheumatica. Hospital Practice. 1990; November 15:71-88

8. Stander PE: Polymyalgia Rheumatica: Clinical Features and Management. Postgraduate Medicine. 1989; 86:131-138

9. Healey LA: Relation of Giant Cell Arteritis to Polymyalgia rheumatica. Clin Rheumatol. 1991; 5:371-378

10. McIntyre JS, Romano J: Is There a Stethoscope in the House (and Is It Used)?: Arch Gen Psychiatry. 1977; 34:1147-1151

11. Patterson CW: Psychiatrists and Physical Examinations: A Survey. Am J Psychiatry. 1978; 135:967-968 
12. Edelsohn G: Unusual-Case Reports: Guillain-Barre Misdiagnosed as Conversion Disorder. Hospital \& Community Psychiatry. 1982; 33:766-767

13. Discipline Committee of the College of Physicians and Surgeons of Ontario: Case 1 (The Case of Steven Yuz). Report of Proceedings: Discipline Committee. January 1992

14. Cameron PM, Kline S, Korenblum M, Seltzer A, Small F: A Method of Reporting Formulation. Can. Psychiatr. Assoc. J. 1978; 23:43-49

15. Engel GL: The Clinical Application of the Biopsychosocial Model. Am J Psychiatry. 1980; 137:535-544

16. Weerasekera P: Formulation: A Multiperspective Model. Canadian Journal of Psychiatry. $1993 ; 38: 351-358$ 